\title{
Methyl oleate deoxygenation for production of diesel fuel aliphatic hydrocarbons over $\mathrm{Pd} / \mathrm{SBA}-15$ catalysts
}

Siew-Pei Lee ${ }^{1+}$ and Anita Ramli ${ }^{2 *+}$

\begin{abstract}
Background: Catalytic deoxygenation is a prominent process for production of renewable fuels from vegetable oil. In this work, deoxygenation of technical grade methyl oleate to diesel fuel aliphatic hydrocarbons $\left(C_{15}-C_{18}\right)$ is evaluated with several parameters including temperature, hydrogen pressure and reaction time in a stirred batch reactor over Pd/SBA-15 catalysts.

Results: Two different SBA-15 morphologies i.e. spherelike and necklacelike structures have been synthesize as supports for Pd active metal. It is found that Pd dispersion on necklacelike SBA-15 is higher than that of spherelike SBA-15. Notably, higher Pd dispersion on necklacelike SBA-15 provides significant deoxygenation efficiency as compared to $\mathrm{Pd} / \mathrm{SBA}$-15-spherelike. Results show that $\mathrm{H}_{2}$ pressures greatly determine the total ester conversion and selectivity to $C_{15}-C_{18}$ aliphatic hydrocarbons. Total ester conversions with $55 \%$ selectivity to $n$-heptadecane are achieved using Pd/SBA-15-necklacelike at $270^{\circ} \mathrm{C}$ and 60 bar $\mathrm{H}_{2}$ pressure within $6 \mathrm{~h}$ reaction time. Gas phase study reveals that formation of $C_{17}$ is generated via indirect decarbonylation when the reaction time is prolonged.
\end{abstract}

Conclusions: Pd/SBA-15-necklacelike catalyst exhibits good catalytic performance with high selectivity to diesellike aliphatic hydrocarbons $\left(C_{15}-C_{18}\right)$. The physicochemical properties of the Pd supported on different SBA-15 morphologies influence the deoxygenation activity of the catalysts. Furthermore, the reaction pathways are governed by the $\mathrm{H}_{2}$ pressure as well as reaction duration.

\section{Background}

Currently, transportation fuel i.e. gasoline, diesel fuel and kerosene are obtained from crude oil refining [1]. Alternative fuels are being sought to overcome the problem associated with dwindling oil reserves and stringent environmental restrictions in greenhouse emissions. To date, government regulations strongly promote utilization of alternative fuels in the effort to reduce the green house gases (GHG) emission as underlined in Kyotol Protocol $[2,3]$. One of the approaches is to investigate the feasibility of vegetable oils to be the potential source for renewable fuels. Several technologies have been discovered to convert the triglycerides into biofuel like derivative of fatty acid

\footnotetext{
* Correspondence: anita_ramli@petronas.com.my

${ }^{\dagger}$ Equal contributors

${ }^{2}$ Fundamental and Applied Science Department, Universiti Teknologi PETRONAS, Bandar Seri Iskandar, 31750 Tronoh, Perak, Malaysia Full list of author information is available at the end of the article
}

methyl ester (FAME) from transesterification of fatty acid $[4,5]$, hydrocracking of biofeedstock into fuel range hydrocarbons [6,7], hydrotreating of triglycerides and fatty acids into hydrocarbon middle distillates as well as production of renewable diesel followed by deoxygenation [8-11]. Although biodiesel production via transesterification is on commercial scale however, this process is highly sensitive to feedstock purity and the higher oxygen content of FAME exhibits poor fuel properties [12]. Thus, biodiesel produced is not compatible for the current combustion engine. Deoxgenation of biofeedstock via hydrodeoxygenation (HDO) or pyrolysis provides an alternative route to produce renewable fuels which can be used as a direct replacement for petroleum sourced hydrocarbons. Nowadays HDO process has been industrialized to form diesel fuel from vegetable oils. Removal of oxygen from triglycerides at elevated temperatures over heterogeneous catalyst in the presence of $\mathrm{H}_{2}$ produces long-chain alkanes from $\mathrm{C}_{4}$ to $\mathrm{C}_{24}$, typically $\mathrm{C}_{16}$ to $\mathrm{C}_{18}$ [13-16].

\section{Chemistry Central}


Supported metal sulfides, NiMo and CuMo sulfides, are the industrialized catalysts for hydroprocessing of petroleum-based feeds. Similarly, these conventional hydrotreating catalysts have been utilized to up-grade vegetable oils to a hydrocarbon-based fuel [17]. Application of this process with the established existing hydroprocessing usually used in a petroleum refinery could eliminate the additional capital costs in construction of new infrastructure. However, metal sulfides used are required with careful handling for the process as well as has to mind for the risk of product with sulfur contamination [18].

Recently, development of sulfur free catalysts was the new approach for transformation of renewable sources into paraffinic liquid fuel. Senol et. al. [15] has reported that catalytic HDO with unsulfided NiMo catalyst is favoured in generating hydrocarbon s with odd number of carbon atoms while sulfided catalyst preferably yield hydrocarbons with even number atoms.

Murzin and co-workers have extensively investigated deoxygenation of triglycerides model compounds such as fatty acids and methyl esters over supported metal catalysts [11,19-21]. Commercial palladium (Pd) supported on activated carbon displayed as the most efficient catalyst in the deoxygenation of stearic acid at a reaction temperature of $300^{\circ} \mathrm{C}$ and 17 bar of $5 \mathrm{vol} \% \mathrm{H}_{2} / \mathrm{Ar}^{1}$. Several reports revealed that supported Pd and Pt catalysts have high selectivity to form hydrocarbons with one carbon less than the corresponding fatty acids in the deoxygenation reaction while formation of $\mathrm{CO}$ and $\mathrm{CO}_{2}$ as the main gaseous products proposed that decarboxylation and decarbonylation were the primary reaction routes [21-25].

Immer et al. [26] provided insight for gas phase composition in catalytic deoxygenation of free fatty acids (FFA) using $\mathrm{Pd} / \mathrm{C}$ catalysts. There was found that deoxygenation pathway is sensitive to the $\mathrm{H}_{2}$ partial pressure applied in the system. Madsen et al. [25] evaluated HDO activities for model fat mixture over $\mathrm{Pt} / \mathrm{\gamma}-\mathrm{Al}_{2} \mathrm{O}_{3}$ under different reaction conditions using a batch reactor and $\mathrm{C}_{15}-\mathrm{C}_{18}$ diesel-like hydrocarbons were formed under $\mathrm{H}_{2}$ rich atmosphere.

To reduce the impact of internal mass transfer limitations and pore blockage, batch deoxygenation of ethyl stearate was studied using Pd supported on the siliceous mesocellular foam (MCF) [27]. However, the study showed that less than $15 \%$ conversion of ethyl stearate was observed at $300^{\circ} \mathrm{C}$ under $\mathrm{N}_{2}$ atmosphere.

Stucky and co-workers discovered hexagonal mesoporous molecular silica that is Santa Barbara amorphous No. 15 (SBA-15) in 1998 [28]. High surface area, large pore volume, high thermal and hydrothermal stabilities and well-defined pore size are the unique characteristics of SBA-15 to use as potential material in catalysis, adsorption, nanoelectronics and etc [29-31]. SBA-15 could be tailored out into different morphologies such as spheres [32], fibers [33] and rodlike [33] through monitoring of the synthesis conditions, thus having different physicochemical properties. The synthetic conditions including acid source [34,35], weight ratio P123/ silica source [36], temperature [37,38], water content [39], $\mathrm{pH}$ value [39], addition of organic salt [38] and shearing flow [40] are the determining factors in fabrication of different forms of SBA-15. Differences in mesophase morphology may be significant for targeted application such as catalysis, separation, internal surface modification and bioimmobilization.

Pd/SBA-15 nanocomposite prepared by Wang et al. [41] demonstrated superior catalytic activity and recyclability for Heck carbon-carbon coupling reaction. Besides, Pd/SBA-15 was also reported showing superior catalytic activity in deoxygenation of stearic acid at $300^{\circ} \mathrm{C}$ under 17 bar of $5 \mathrm{vol} \% \mathrm{H}_{2} / \mathrm{Ar}$ as compared to $\mathrm{Pd} / \mathrm{C}$, the conventional deoxygenation catalyst [42]. Hydrodeoxygenation of methyl oleate was studied over $\mathrm{Ni}_{2} \mathrm{P} / \mathrm{SBA}-15$ in a fixed-bed reactor and showed that uniform dispersion of NiP on SBA-15 resulted in higher conversion of esters and selectivity of long-chain paraffin [16].

Supported Pd on SBA-15 with $3 \mathrm{wt} \%$ as well as $5 \mathrm{wt} \%$ were tested for deoxygenation of stearic acid. The catalyst with $3 \mathrm{wt} \%$ showed highest catalytic activity and provided $90 \% n$-heptadecane selectivity [42]. Nevertheless, it found that $3.8 \mathrm{wt} \%$ supported Pd on SBA-15 was the optimum Pd loading for deoxygenation of methyl oleate [43]. In this regard, catalytic deoxygenation of methyl oleate to $\mathrm{C}_{15}-\mathrm{C}_{18}$ aliphatic hydrocarbons which are the major components find in diesel fuel is investigated over supported $3.8 \mathrm{wt} \% \mathrm{Pd}$ nanoparticles on two different SBA-15 mesostructures, necklacelike and spherelike, using batch stirred reactor. Methyl oleate is selected as a feedstock for this study is due to presence of major amount in fatty acid monoesters molecules which are mostly found in vegetable oil.

\section{Results}

\section{Phase structure and physicochemical characterization}

Small angle X-ray Diffraction (XRD) patterns of SBA15 and Pd/SBA-15 samples synthesized are showed in Figure 1. An intense peak in the XRD pattern at $2 \Theta$ within $0.8-0.9^{\circ}$ (Figure 1) and two well-resolved peaks at $1.6-2.0^{\circ}$ (Figure 1 insertion) are the (100), (110) and (200) diffractions of the ordered hexagonal lattice $(p 6 \mathrm{~mm})$ with continuous silica walls of SBA-15.

Figure 2 shows the nitrogen adsorption-desorption isotherms for siliceous SBA-15 and Pd/SBA-15 samples. Both necklacelike SBA-15 and spherelike SBA-15 samples exhibits type-IV isotherms according to International Union of Pure and Applied Chemistry (IUPAC) 


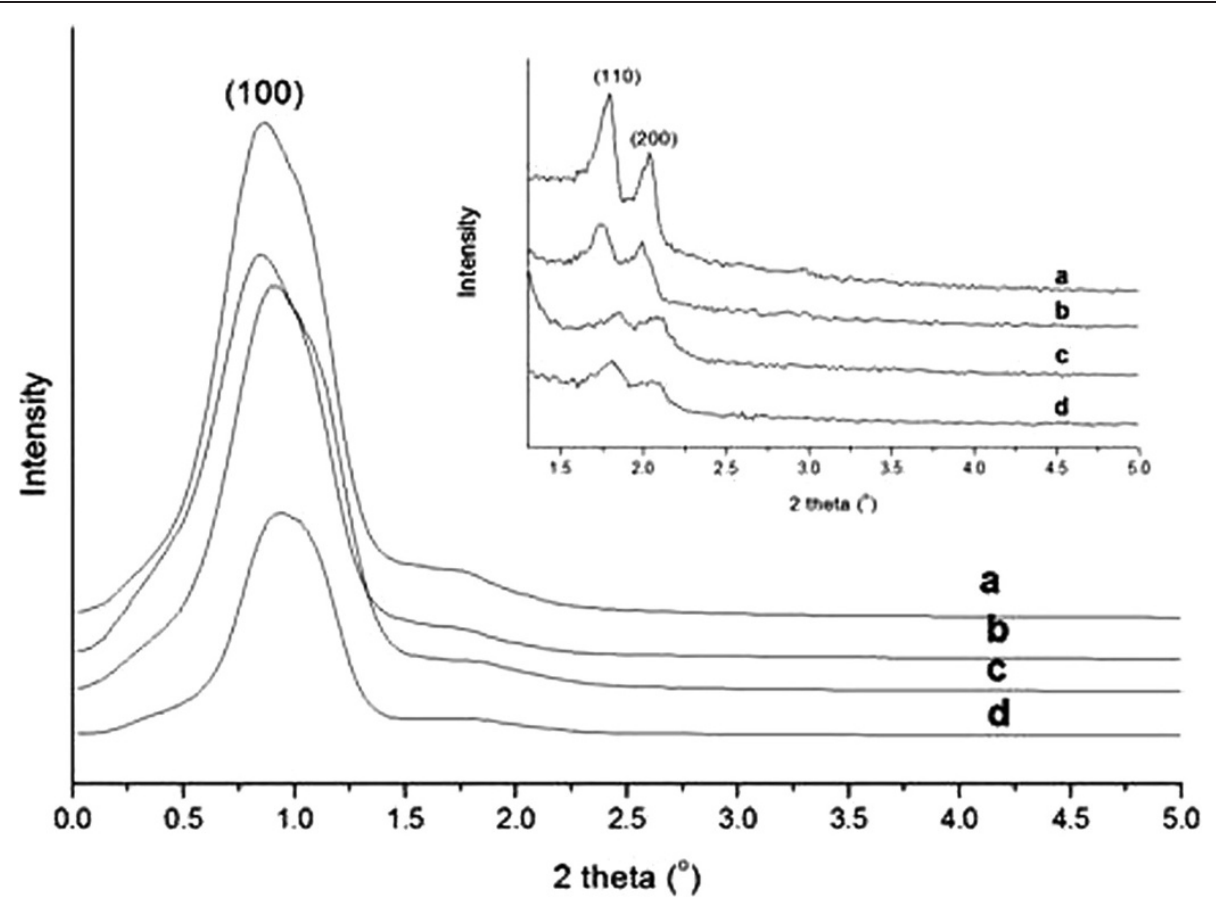

Figure 1 XRD patterns at low diffraction angles for Pd supported on SBA-15 structure. (a) SBA-15-necklacelike calc., (b) 3.8 wt\% Pd/SBA15-necklacelike (c) SBA-15-spherelike calc., (d) 3.8 wt\% Pd/SBA-15-spherelike. Insert shows the local magnification of small-angle X-ray diffraction patterns for $\mathrm{Pd} / \mathrm{SBA}-15$.

classification with type-H1 hysteresis loop which is a typical characteristics exhibited by mesoporous silica.

The textural properties such as Brunauer-EmmetTeller (BET) surface area, average pore diameter and cumulative adsorption pore volume obtained by BarretJoyner-Halenda (BJH) are given in Table 1. SBA-15 materials prepared show high specific surface area in the range of $783-432 \mathrm{~m}^{2} / \mathrm{g}$ and high specific pore volume with $0.88-0.67 \mathrm{~cm}^{3} / \mathrm{g}$.

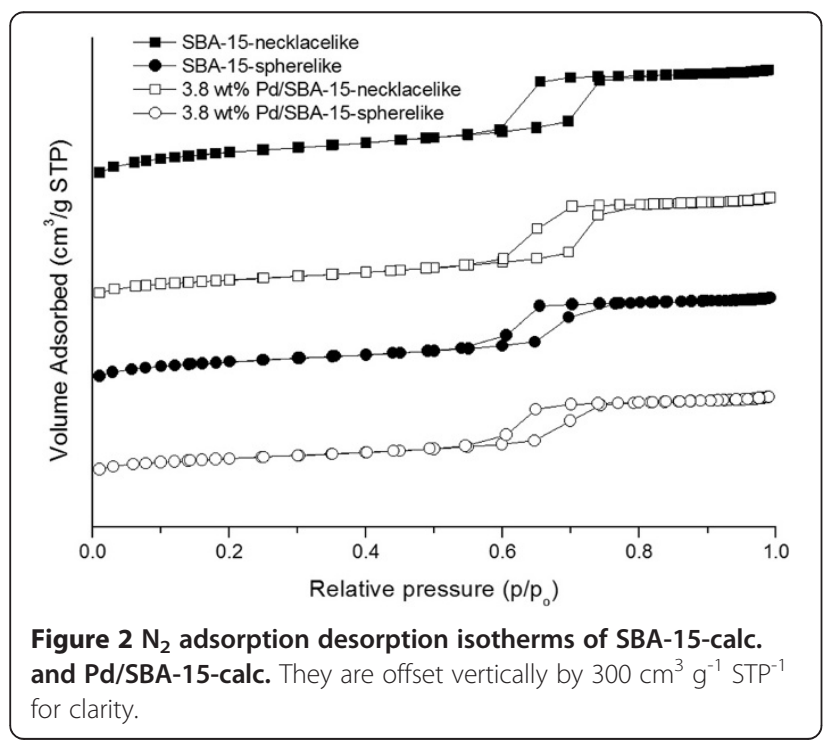

BET surface area for both SBA-15 morphologies decreases significantly with $\mathrm{Pd}$ incorporation although minor changes in the specific pore volume are observed.

The pore size distribution curves of short spherelike and necklacelike samples which are calculated from adsorption branch by BJH shows narrow pore size distribution around a diameter of $5.5-6.5 \mathrm{~nm}$ (as shown in Figure 3). However wider distribution in the pores of $\mathrm{Pd} / \mathrm{SBA}-15$ samples is observed. As a result, the average pore diameter reported is bigger than that of parent SBA-15 (Table 1).

Field Emission Scanning Electron Miscroscopy (FESEM) image shows the formation of different lengths of necklacelike SBA-15 which possess bundles of micro-sized rod (Figure 4a). On contrary, individual spherelike particles are observed from Figure 4b. High resolution FESEM micrograph in Figure 5 clearly shows that necklacelike SBA-15 mesoporous silica is packed with well-ordered 2D hexagonal array.

Low acceleration voltage FESEM and Energy-dispersive $\mathrm{X}$-ray (EDX) pattern of $\mathrm{Pd} / \mathrm{SBA}-15$ are presented in Figure 6 (a) and (b). It is observed that $\mathrm{PdO}$ nanoparticles are distributed on external surface of SBA-15 where the presence of $\mathrm{Pd}$ element is further confirmed from the $\mathrm{Pd}$ signals generated in EDX pattern [inserted Figure 6 (a) \& (b)]. Figure 7 (a) and (b) shows the particle size distribution derived from the low acceleration voltage FESEM images by surveying 100 particles. It should be noted that 
Table 1 The main characteristics of mesoporous silica SBA-15 and Pd/SBA-15 composites: $\mathrm{S}_{\mathrm{BET}}$, specific surface area $\left(\mathrm{m}^{2} / \mathrm{g}\right), \mathrm{V}_{\mathrm{p}}$, pore volume $\left(\mathrm{cm}^{3} / \mathrm{g}\right), \mathrm{D}_{\mathrm{p}}$, average pore diameter $(\mathrm{nm})$

\begin{tabular}{lccccc}
\hline Sample $^{\mathbf{a}}$ & Actual Pd content $^{\mathbf{b}}(\mathbf{w t} \%)$ & $\mathbf{S}_{\mathbf{B E T}}^{\mathbf{c}}\left(\mathbf{m}^{\mathbf{2}} \mathbf{/ g}\right)$ & $\mathbf{V}_{\mathbf{p}}^{\mathbf{d}}\left(\mathbf{c m}^{\mathbf{3}} \mathbf{g}\right)$ & $\mathbf{D}_{\mathbf{p}}^{\mathbf{d}}(\mathbf{n m})$ & Pd dispersion $^{\mathbf{e}}(\%)$ \\
\hline SBA-15-N & - & 783 & 0.88 & 5.6 & - \\
3.8 wt\% Pd/SBA-15-N & 3.2 & 482 & 0.81 & 6.4 & 39.0 \\
SBA-15-S & - & 561 & 0.68 & 5.6 & - \\
3.8 wt\% Pd/SBA-15-S & 3.7 & 432 & 0.67 & 6.0 & 19.0 \\
\hline
\end{tabular}

SBA-15-N: necklacelike SBA-15; SBA-15-S: spherelike SBA-15.

${ }^{\mathrm{a}}$ Nominal palladium loading.

bDetermined by ICP-MS.

'Calculated by BET method.

${ }^{\mathrm{d} C}$ Calculated from adsorption branch by BJH method.

${ }^{\mathrm{e}}$ Measured by $\mathrm{H}_{2}$ chemisorption.

the sizes of the PdO nanoparticles formed on the external surface of necklacelike SBA-15 are distributed uniformly in a range of $2-5 \mathrm{~nm}$ [Figure 7 (a)]. Thus, Pd/SBA-15necklacelike has a narrow particle size distribution with largest size of $18 \mathrm{~nm}$. In comparison, a broader particle size distribution is observed for $\mathrm{Pd} / \mathrm{SBA}-15$-spherelike and the largest particle size measured is $27 \mathrm{~nm}$.

$\mathrm{H}_{2}$ pulse chemisorption is used to measure Pd dispersion adsorbed on SBA-15 surface (Table 1). 39\% Pd dispersion is found on necklacelike SBA-15 however, spherelike SBA-15 only provides 19\% Pd dispersion.

\section{Catalyst evaluation}

Liquid phase deoxygenation of triglyceride surrogate molecules, methyl oleate to $\mathrm{C}_{15}-\mathrm{C}_{18}$ aliphatic hydrocarbons is investigated in a stirred batch reactor over $3.8 \mathrm{wt} \% \mathrm{Pd} / \mathrm{SBA}-15$ on two different SBA-15 morphologies as discussed before. Catalytic deoxygenation of methyl oleate (70\% technical grade) is studied using $\mathrm{Pd} /$ SBA-15-necklacelike (N1) and Pd/SBA-15-spherelike (S1) catalysts at $270^{\circ} \mathrm{C}, 60$ bar $\mathrm{H}_{2}$ pressure, catalyst loading of $3 \mathrm{wt} \%$ and $6 \mathrm{~h}$ reaction duration.

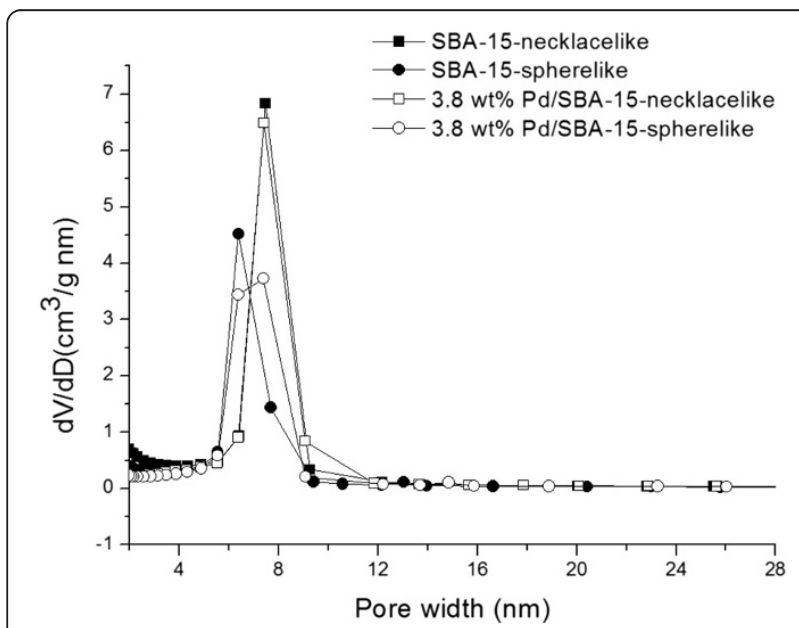

Figure 3 Pore size distribution of SBA-15-calc. and $3.8 \mathrm{wt} \% \mathrm{Pd} /$ SBA-15-calc.
The feedstock used for the experiments is a technical grade of methyl oleate, containing a mixture of $76 \%$, methyl oleate, $5 \%$ of methyl palmitoleate and $18 \%$ of methyl palmitate. Similar total ester conversion that is about 95\% as shown in the Table 2 is observed for both catalysts since majority of unsaturated esters are converted at $60 \mathrm{bar} \mathrm{H}_{2}$ pressure. Formation of saturated esters was reported to be more prominent under high $\mathrm{H}_{2}$ pressure [21]. However, higher Pd dispersion on necklacelike SBA-15 that is 39\% provides superior selectivities for $\mathrm{C}_{15}$ to $\mathrm{C}_{18}$ aliphatic hydrocarbons as compared with $\mathrm{Pd}$ supported on spherelike structures (Figure 8). Result shows that $55 \%$ selectivity to $n$-heptadecane was achieved using $\mathrm{Pd} / \mathrm{SBA}-15$-necklacelike catalyst as compared to only $16 \%$ selectivity shown by Pd/SBA-15-spherelike catalyst, indicating that Pd dispersion has significant influence in the catalyst performance.

The effect of temperature on the catalytic activity is investigated using Pd supported by necklacelike SBA-15. Figure 9 shows the selectivity to $C_{15}$ to $C_{17}$ aliphatic hydrocarbons is low within $3 \mathrm{~h}$ duration over the temperature range from $250-300^{\circ} \mathrm{C}$ at 25 bar $\mathrm{H}_{2}$ pressure. However, formation of $n$-octadecane was not observed in the product mixture within $3 \mathrm{~h}$ of reaction.

Effect of hydrogen pressure on the selectivity of linear hydrocarbon is studied (Figure 10). Reaction temperature of $270^{\circ} \mathrm{C}$ is selected for further investigations due to the total yield of paraffinic hydrocarbons obtained is higher in amongst of temperature investigated. It is important to notice that ester conversion and selectivity of paraffin are sensitive to pressure variation at $270^{\circ} \mathrm{C}$ (Figure 10). Accordingly, increment of the total ester conversion and selectivity of $\mathrm{C}_{15}$ to $\mathrm{C}_{18}$ paraffinic hydrocarbons are in parallel with the reaction pressure from 25 bar to 60 bar $\mathrm{H}_{2}$ pressure. The selectivity for $\mathrm{C}_{15}$ to $\mathrm{C}_{18}$ long chain hydrocarbons is relatively low from 25 bar to $35 \mathrm{bar}_{2}$ pressure as compared with 60 bar $\mathrm{H}_{2}$ pressure at $270^{\circ} \mathrm{C}$ within $3 \mathrm{~h}$ reaction duration. At 60 bar, the selectivity for $n$ heptadecane is exceptionally high than other aliphatic hydrocarbons at 60 bar $\mathrm{H}_{2}$ pressure. On the other hand, a decrease in ester conversion from 60 to $80 \mathrm{bar}_{2}$ pressure 

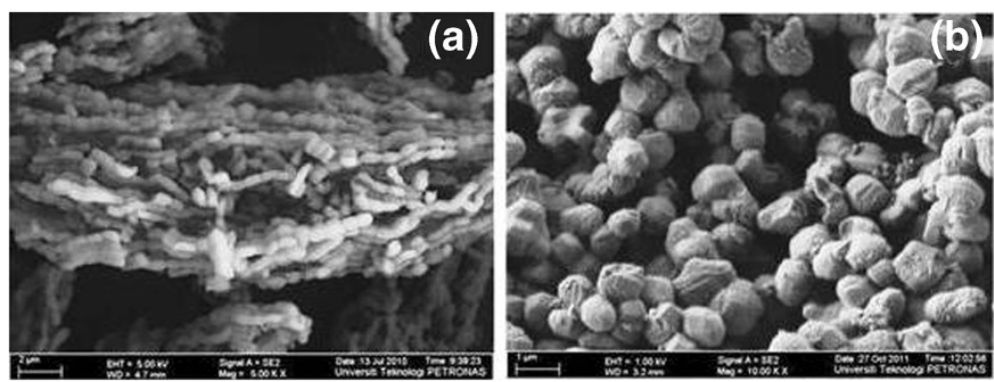

Figure 4 FESEM images of the SBA-15 catalysts. (a) necklacelike SBA-15 and (b) spherelike SBA-15.

and suppression for yield of $n$-alkanes formation are observed. Obviously, deoxygenation of methyl oleate using $\mathrm{Pd} / \mathrm{SBA}-15$ is less pronounced at 80 bar.

Figure 11 shows that the composition of carbonaceous gases for different pressure at $270^{\circ} \mathrm{C}$ in $\mathrm{H}_{2}$. Still, $\mathrm{CO}_{2}$ is detected as the major carbonaceous gas product. However, $\mathrm{CO}_{2} / \mathrm{CO}$ ratio decreases when $\mathrm{H}_{2}$ pressure increases (Figure 11). The concurrent reduction of the $\mathrm{CO}_{2}$ concentration and increment of methane formation as increasing of $\mathrm{H}_{2}$ pressure may be due to the hydrogenation of $\mathrm{CO}_{2}$ to methane.

Batch deoxygenation of mehyl oleate with reaction duration is further attempted at $270^{\circ} \mathrm{C}$ and 60 bar $\mathrm{H}_{2}$ using 3.8 wt\% Pd/SBA-15 necklacelike catalyst (Figure 12). The catalyst is exceptionally active for hydrocarbons production when the reaction duration are extended to $8 \mathrm{~h}$ since the selectivity to $\mathrm{C}_{15}-\mathrm{C}_{18}$ hydrocarbons increases up to approximately 57\% (Figure 12). Total esters conversion attained $95 \%$ but it is reached a plateau after $6 \mathrm{~h}$ at $270^{\circ} \mathrm{C}$ and 60 bar $\mathrm{H}_{2}$ pressure. But no significant selectivity improvement for $C_{15}$ to $C_{18}$ long chain hydrocarbons is observed after $8 \mathrm{~h}$ of reaction.

At $270^{\circ} \mathrm{C}$ and 60 bar hydrogen pressure, the selectivity of $n$-heptadecane was relatively low during the reaction

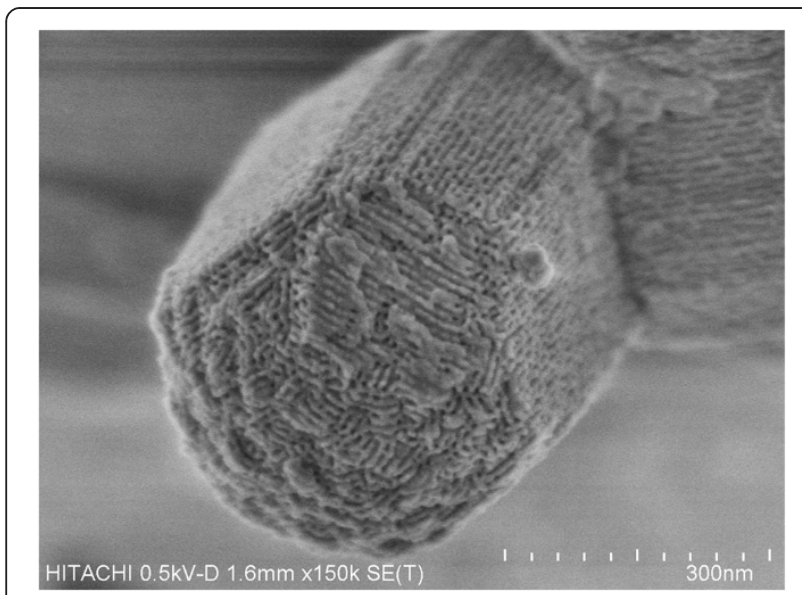

Figure 5 Low accelerating FESEEM image of SBA-15 with honeycomb disposition of pore entrance. time of $1 \mathrm{~h}$ and no others paraffinic hydrocarbons are found in the reaction mixture (Figure 13). Solely $n$ heptadecane is found during $1 \mathrm{~h}$ reaction time may imply that decarboxylation or decarbonylation is predominant in the initial reaction stage. It should, however, be noted that, no aromatic and unsaturated $C_{17}$ compounds are detected in all time stream.

Figure 13 shows the evolution of gas-phase products with reaction time on $3.8 \% \mathrm{Pd} / \mathrm{SBA}-15$-necklacelike at $270^{\circ} \mathrm{C}$ and 60 bar $\mathrm{H}_{2}$ pressure. $\mathrm{CO}_{2}, \mathrm{CO}$ and $\mathrm{CH}_{4}$ are evolved concomitantly during the reaction progression. Unlike the increase in the concentration of $\mathrm{CO}$ with time, the $\mathrm{CO}_{2}$ evolution decreases monotonically with reaction time. $\mathrm{CO}_{2} / \mathrm{CO}$ ratio is increased within $3 \mathrm{~h}$ reaction while subsequently there is a sharp decrease in $\mathrm{CO} / \mathrm{CO}_{2}$ ratio (Figure 13). Besides, the methane content is increased remarkable in the total of carbonaceous gas products from 6 to $8 \mathrm{~h}$ reaction (Figure 13).

\section{Discussion}

Ordered hexagonal pore array structure of SBA-15 with $\mathrm{Pd}$ incorporated is preserved since no significant change between the diffraction patterns which indexed as (100), (110) and (200) for Pd/SBA-15 and SBA-15 materials (Figure 1). However, it is observed that the intensity of the diffraction peaks at $2 \theta$ between $1.6-2.0^{\circ}$ decreases significantly in necklacelike structure as compared to spherelike structure (inserted Figure 1). A decrease in peak intensity is attributed of distribution of the $\mathrm{Pd}$ on the external surface of the SBA-15. This means that more Pd particles are distributed on the external surface of necklacelike structure as compared to spherelike structure, thus resulted in a more significant reduction in surface area of necklacelike structure compared to spherelike structure.

A shift of the diffraction peaks to lower angles is identified from $\mathrm{Pd} / \mathrm{SBA}-15$ samples, reflecting an increase in unit cell parameter of the SBA-15 framework. As reported by other researchers [44-46], this feature is because of the metals substitution into mesoporous molecular sieves. Therefore, substitution of Pd into SBA-15 framework 

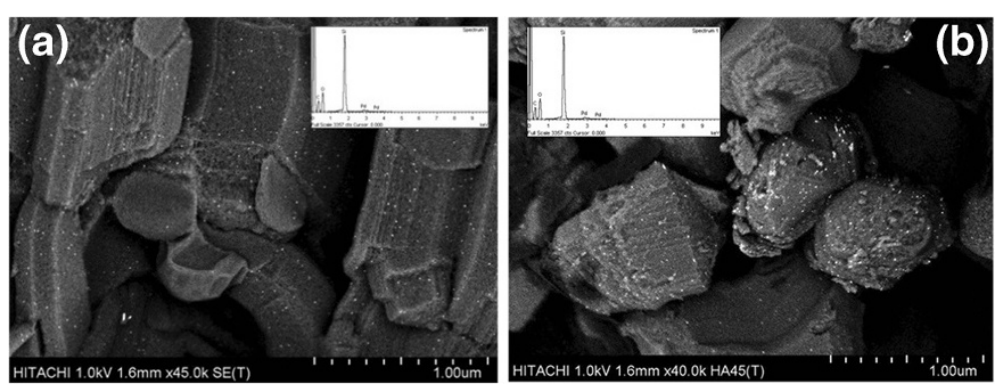

Figure 6 Low accelerating FESEM voltage images of Pd/SBA-15. (a) Pd/SBA-15-necklacelike and (b) Pd/SBA-15- spherelike. Insert shows the EDX patterns of $\mathrm{Pd} / \mathrm{SBA}-15$.

might be the main reason to increase the unit cell parameters of the SBA-15 mesoporous structure.

Hysteresis loop as observed in Figure 2 is due to the $\mathrm{N}_{2}$ capillary condensation in cylindrical mesoporous channels. Besides, no significant change of isotherm pattern from Pd/SBA-15 samples suggests that SBA-15 template is preserved with anchoring of Pd ion via impregnation. Necklacelike SBA-15 synthesized provides larger surface area and higher pore volume than spherelike SBA-15. This may be attributed to the formation of larger micelles quantity as a result of stirring during synthesis of necklacelike SBA-15. The micelles are then removed during calcination resulting in an increase in the number of pores thus an increase in the total surface area and total pore volume [32].

The significant reduction in surface area without significant decrease in pore volume (Table 1) may indicate that most of the PdO particles are distributed on the external surface of the support as compared to in the pores, thus resulted in a more significant reduction in the surface area as compared to the reduction in pore volume. However, wider pore distribution for Pd/SBA-15 samples was observed after incorporation of Pd in SBA15 (Figure 3). As a result, the slight increase in average pore size of Pd-incorporated catalyst is due to an increase in pore distribution.
Better Pd distribution on necklacelike SBA-15 as compared to spherelike SBA-15 (Table 1) due to the most of the smaller PdO particles, ranged in $2-5 \mathrm{~nm}$, are being formed on the surface of the necklacelike structure [Figure 7 (a)]. This may be attributed the larger surface area available in the necklacelike support, thus enable a better Pd dispersion. In addition, larger particle size found on spherelike SBA-15 is resulted from the agglomeration of $\mathrm{PdO}$ nanoparticles during calcinations process.

Stirring flow applied in reaction mixture governs the formation of different SBA-15 morphologies [32,39]. Exerted shearing stress from continuous stirring promotes intermicelle interactions while short cylindrical silicate-surfactant micelles are lengthened along the flow direction and joined into longer silicas structure [Figure 4 (a)]. In addition, higher intensity of diffraction peaks at $2 \theta$ between $1.6-2.0^{\circ}$ is observed for necklacelike SBA15 as compared to spherelike SBA-15 (inserted Figure 1). Notably, the crystallinity of necklacelike SBA-15 is increased as the synthesis temperature was raised to $80^{\circ} \mathrm{C}$. Therefore, it found that elongation of the longer silicas rod units under higher temperature leads to the formation of necklacelike SBA-15 structure.

It is found that better Pd/SBA-15-necklacelike contributes higher deoxygenation efficiency for aliphatic
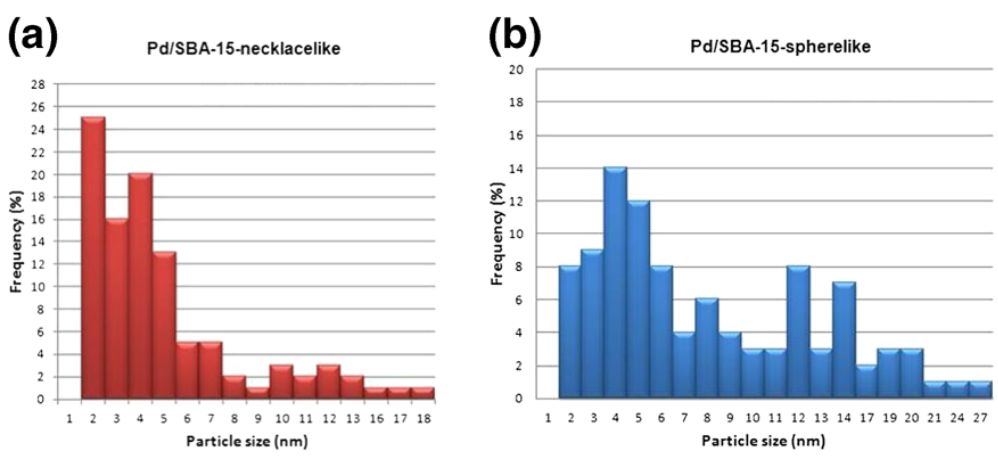

Figure 7 Particles distribution of Pd/SBA-15. (a) Pd/SBA-15-necklacelike and (b) Pd/SBA-15- spherelike. 
Table 2 Total ester conversion with supported Pd on two different morphologies of SBA-15

\begin{tabular}{cccc}
\hline Catalyst & $\begin{array}{c}\text { BET surface } \\
\text { area }\left(\mathbf{m}^{\mathbf{2}} \mathbf{g}\right)\end{array}$ & Pd dispersion $^{\text {a }}$ (\%) & $\begin{array}{c}\text { Total ester } \\
\text { conversion (\%) }\end{array}$ \\
\hline N1 & 482.2 & 39.2 & 95 \\
S1 & 431.9 & 18.5 & 94.3 \\
\hline
\end{tabular}

${ }^{\mathrm{a}}$ Metal dispersion determined by $\mathrm{H}_{2}$ pulse chemisorptions.

N1: 3.8 wt\% Pd/SBA-15-necklacelike.

S1: $3.8 w t \%$ Pd/SBA-15-spherelike.

hydrocarbon formation instead of Pd/SBA-15-spherelike (Figure 8). The increased of surface-to-volume ratio due to higher Pd dispersion on necklacelike SBA-15 may enhance the adsorption of active Pd metal to methyl oleate molecules.

Pd/SBA-15-necklacelike catalyst is considered active over the temperature range studied as the total esters conversion achieved is more than $80 \%$ after $3 \mathrm{~h}$ reaction (Figure 9). It is observed that majority of methyl octadecanoate and methyl hexadecanoate are formed via hydrogenation of the unsaturated methyl esters as the reaction intermediates. Besides, the off-line gas analysis shows that $\mathrm{CO}_{2}$ is the main carbonaceous gas product.

Hydrogenation of double bond in methyl esters molecules proceed faster than deoxygenation of the methyl esters functionalities within $250-300^{\circ} \mathrm{C}$ in $3 \mathrm{~h}$ reaction period. Majority formation of $\mathrm{CO}_{2}$ in a gas phase reveals that supported Pd catalyst is active and selective to produce $n$-heptadecane via decarboxylation instead of hydrodeoxgyenation (as shown in Figure 14).

Low selectivity of $C_{15}$ to $C_{18}$ aliphatic hydrocarbons (Figure 10) is due to saturation of dissolved $\mathrm{H}_{2}$ in reaction medium under high $\mathrm{H}_{2}$ pressure (80 bar), which active metal Pd interaction with methyl oleate molecules is inhibited like described by Madsen et al. [25]. Reaction moves toward decarbonylation route in a presence of higher $\mathrm{H}_{2}$ pressure results decrease of $\mathrm{CO}_{2} / \mathrm{CO}$ ratio

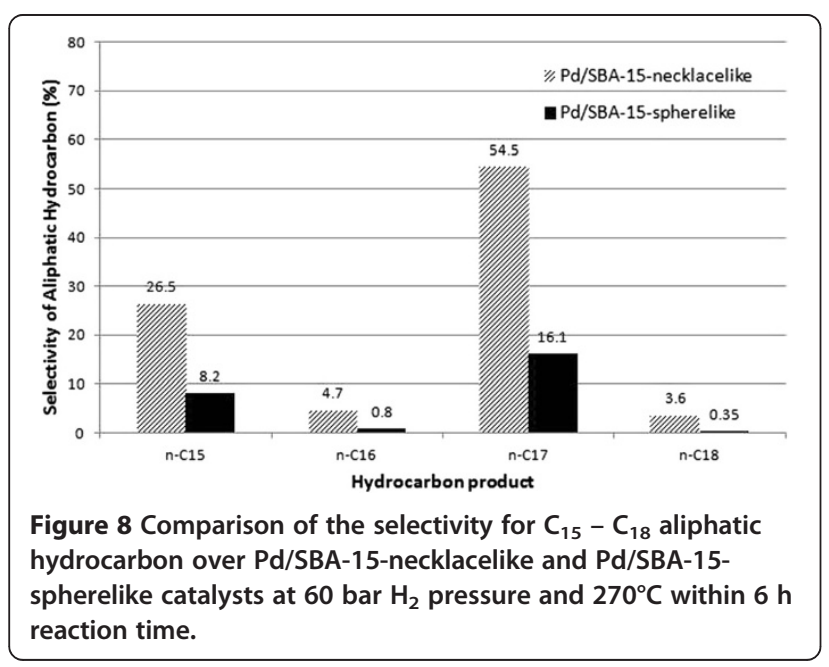

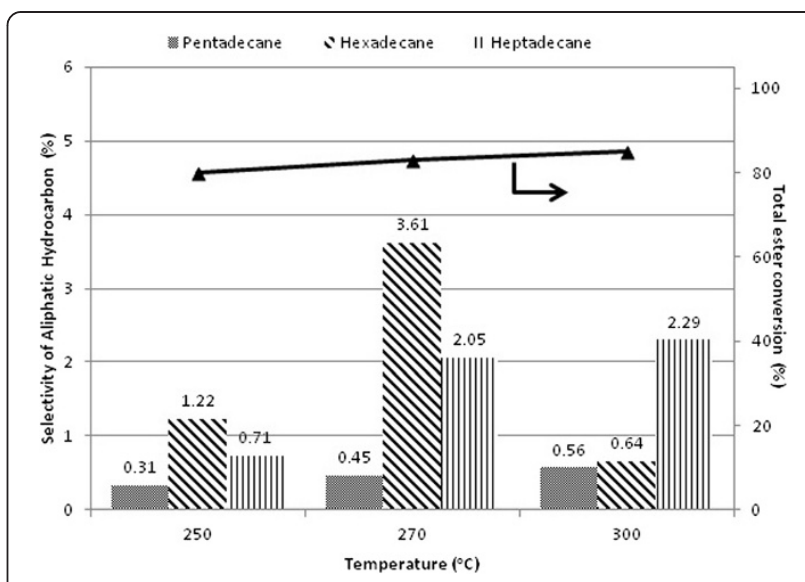

Figure 9 Selectivity for $C_{15}-C_{17}$ aliphatic hydrocarbon and total ester conversion with reaction temperature variation over $\mathrm{Pd} /$ SBA-15-necklacelike at $\mathrm{H}_{2}$ pressure 25 bar in $3 \mathrm{~h}$ reaction time.

(Figure 11). The switchover phenomenon observed enhances the finding reported by Boda et al. [8] and Immer et al. studies [26]. It is expected that methanation is facile under high $\mathrm{H}_{2}$ pressure condition like other reports mentioned [47]. But it might be possible that minor methane formation is come from the $\mathrm{CO}$ hydrogenation as suggested by Donnis et al. [10].

$55 \%$ selectivity to $n$-heptadecane in $6 \mathrm{~h}$ reaction time demonstrates that Pd supported on necklacelike SBA-15 exhibits high deoxygenation efficiency to methyl oleate (Figure 12). In comparison to the work reported by Snare et al. [21], only about $25 \%$ selectivity to the main product $n$-heptadecane was obtained from technical grade of methyl oleate using microporous $\mathrm{Pd} / \mathrm{C}$. Therefore, it is true to some extent that $\mathrm{Pd} / \mathrm{SBA}-15$ catalyst outperforms than $\mathrm{Pd} / \mathrm{C}$ either using complex mixture of unsaturated esters in the present study or pure stearic acid itself [42]. However, insufficient contact time for interaction of active metal $\mathrm{Pd}$ and methyl esters

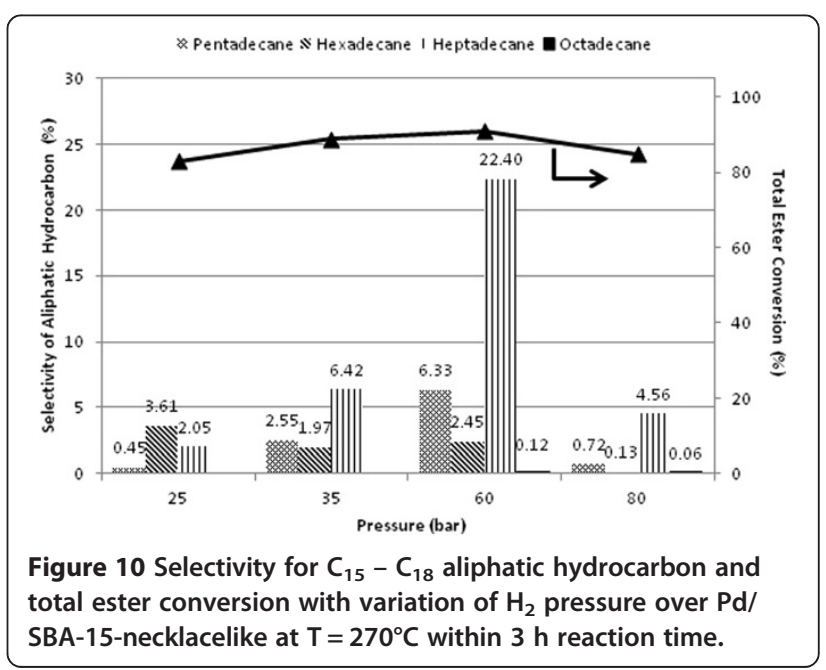




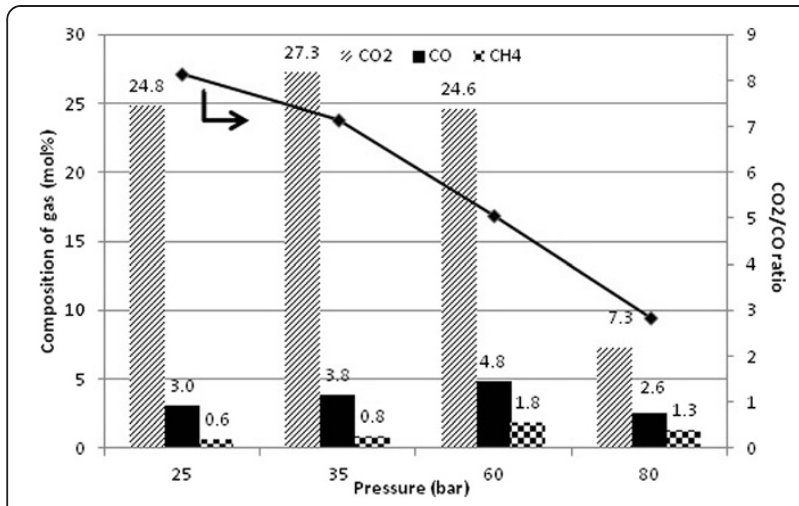

Figure 11 Composition of main carbonaceous gases detected and $\mathrm{CO}_{2} / \mathrm{CO}$ ratio with over $3.8 \mathrm{wt} \% \mathrm{Pd} / \mathrm{SBA}-15$-necklacelike at 60 bar $\mathrm{H}_{2}$ pressure and $\mathrm{T}=270^{\circ} \mathrm{C}$.

molecules into paraffinic hydrocarbons gives low selectivity of $n$-heptadecane in $1 \mathrm{~h}$ reaction.

As indicated in Figure 12, Pd supported on SBA-15 does not promote deoxygenation of fatty acids or ester functionalities via HDO pathway. In contrast, supported Pd catalyst is active in decarboxylation and/or decarbonylation route for elimination of $\mathrm{C}=\mathrm{O}$ molecules to form odd-carbon-number of hydrocarbons. Isomers and unsaturated hydrocarbons are absence since Pd has been known as the strong hydrogenation agent. It is notably that isomerization and dehydrogenation are hardly involved in $\mathrm{H}_{2}$ atmosphere [11].

Production of $\mathrm{CO}$ and $\mathrm{CO}_{2}$ during decarboxylation/ decarbonylation is crucial to understand plausible reaction path for the production of linear hydrocarbons. $n$ alkanes formation are preferable via decarboxylation within $3 \mathrm{~h}$ initial reaction time (as shown in Figure 13). However, highly dissolved $\mathrm{H}_{2}$ in the alkane solvent in a longer reaction time under high $\mathrm{H}_{2}$ pressure may push either decarbonylation or reverse water gas shift equilibrium towards increased $\mathrm{CO}$ formation in a gas phase. As

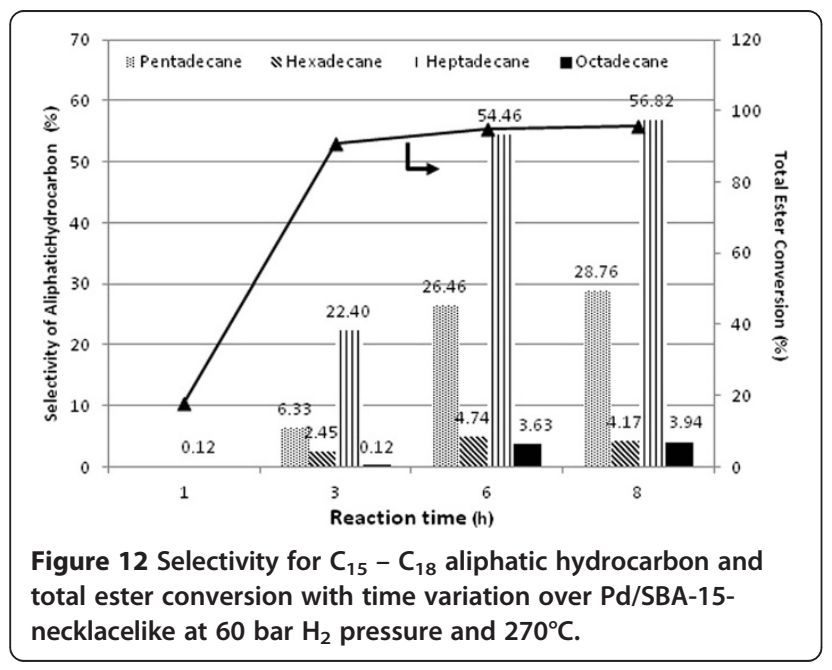

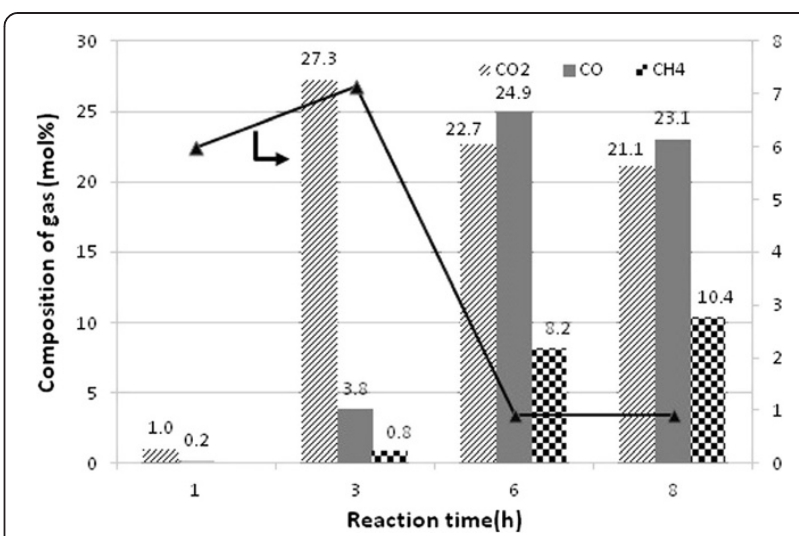

Figure 13 Composition of main carbonaceous gases detected and $\mathrm{CO}_{2} / \mathrm{CO}$ ratio with over $3.8 \mathrm{wt} \% \mathrm{Pd} / \mathrm{SBA}-15$-necklacelike at 60 bar $\mathrm{H}_{2}$ pressure and $\mathrm{T}=270^{\circ} \mathrm{C}$.

previously showed in Figure 12 selectivity of $n$ heptadecane is significantly increased when reaction time is prolonged. As a result, switchover product selectivity from $\mathrm{CO}_{2}$ to $\mathrm{CO}$ observed reveals that conversion of methyl oleate to $n$-heptadecane is predominant via indirect decarbonylation. Methyl stearate, hydrogenated methyl oleate, proceeds via partial reduction of the carboxylic group to corresponding $n$-octadecanal followed by released of $\mathrm{CO}$ to form $n$-heptadecane as increasing of time-on-stream (Figure 14). High methanation of $\mathrm{CO}_{2}$ or $\mathrm{CO}$ attributes significant amount of methane in a gas phase as increased of reaction time. This finding shows that $\mathrm{Pd} / \mathrm{SBA}-15$ is active to reduce fully the oxidized carbon into methane.

\section{Conclusions}

Necklacelike SBA-15 with high surface area is a great support to disperse Pd nanoparticles. Nanosized Pd

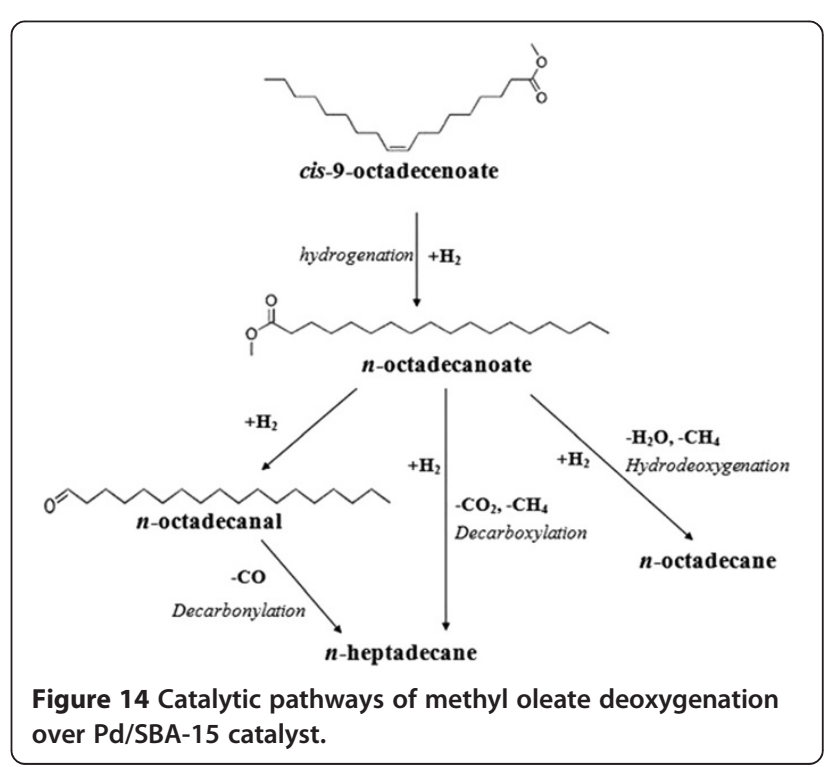


particles anchored on necklacelike SBA-15 shows better deoxygenation reactivity than $\mathrm{Pd} / \mathrm{SBA}-15$-spherelike catalyst. Exceptionally high conversion of $70 \%$ technical grade of methyl oleate into diesel fuel aliphatic hydrocarbons $\left(C_{15}-C_{18}\right)$ is achieved at mild temperature i.e. $270^{\circ} \mathrm{C}$ and high $\mathrm{H}_{2}$ pressure, 60 bar in $6 \mathrm{~h}$ reaction time using batch reactor. Indirect decarbonylation pathway is dominant as increasing of reaction time. Here is found that $\mathrm{Pd} / \mathrm{SBA}-15$ is keenly involved in methanation during reaction progression. Deoxygenation of methyl oleate, surrogate molecule of vegetable oil, in the present work is greatly influenced by different support morphologies and reaction parameters.

\section{Methods}

\section{Catalyst preparation}

Necklacelike mesoporous SBA-15 was prepared by dissolving Pluronic P123 (PEO20PPO70PEO20) (Aldrich) in $2 \mathrm{M}$ hydrochloric acid $(\mathrm{HCl})$ (Merck) at $35^{\circ} \mathrm{C}$ before addition of tetraethylorthosilicate (TEOS) (Merck). The reaction mixture was then continuously stirred at $35^{\circ} \mathrm{C}$ for $24 \mathrm{~h}$. Next, the solution temperature was raised to $80^{\circ} \mathrm{C}$ and stirred another $48 \mathrm{~h}$. Meanwhile, spherelike SBA-15 was prepared by vigorously stirring the reaction mixture at $35^{\circ} \mathrm{C}$ for 10 minutes. Subsequently, the solution mixture was kept in isothermally static condition for $6 \mathrm{~h}$. Template removal of SBA-15 was achieved by calcination in air at $550^{\circ} \mathrm{C}$ for $4 \mathrm{~h}$. SBA- 15 supported palladium catalyst, Pd/SBA-15 with $3.8 \mathrm{wt} \%$ Pd was prepared by impregnation method, filtered, air dried and calcination in air at $550^{\circ} \mathrm{C}$ for $4 \mathrm{~h}$.

\section{Catalyst characterization}

The concentration of Pd (wt\%) incorporated into SBA15 was measured by Inductively Coupled Plasma-Mass Spectrometer (ICP-MS), Agilent 7500 series. The BET surface area and pore diameters of the samples were determined by nitrogen adsorption-desorption isotherms measurement at $77 \mathrm{~K}$ using Quantachrome Autosorb 6B. XRD patterns of the catalysts were recorded with Bruker AXS D8 Discover equipped with general area diffraction detector system (GADDS) working with CoK $\alpha 1$ $(1.5418 \AA)$. In order to obtain higher solution of low angle XRD patterns, all the calcined samples were recorded on Bruker D8 Advance Powder diffractormeter (CuK $\alpha 1$ radiation, $\lambda=1.5406 \AA$ ).

The metal dispersion of supported palladium catalysts were investigated by $\mathrm{H}_{2}$ chemisorption. Pulse chemisorption on reduced palladium catalysts was performed at $70^{\circ} \mathrm{C}$ using Temperature Programmed Desorption Reduction and Oxidation (TPDRO) 1100 (Thermo Finnigan). The number of exposed palladium atoms on the surface was calculated by the total amount of hydrogen adsorped using the molar ratio between $\mathrm{Pd}: \mathrm{H}_{2}$ as 0.5 [19].

FESEM coupled with EDX analysis was performed on Supra 55 VP, Carl Zeiss scanning electron microscopy. Low accelerating voltage FESEM image of the catalysts were taken using Hitachi SU-8000.

Transmission Electron Microscope (TEM) micrographs were captured by Carl Zeiss LIBRA 200 (with an accelerating voltage $200 \mathrm{kV}$ ).

\section{Catalyst evaluation}

Evaluation of the Pd/SBA-15 performance in deoxygenation reaction was carried out in a $200 \mathrm{ml}$ Hastelloy autoclave. The catalysts were primarily reduced with $5 \mathrm{vol} \% \mathrm{H}_{2} / \mathrm{Ar}$ at $300^{\circ} \mathrm{C}$ for $1 \mathrm{~h}$ while, the autoclave was charged with $10 \mathrm{wt} \%$ of model feedstock, methyl oleate (70\% Aldrich) in $n$-heptane. Then, the active catalysts were charged in the reactor vessel under inert atmosphere and the reaction was conducted at temperature between $250-300^{\circ} \mathrm{C}$ and $\mathrm{H}_{2}$ pressure range from 25 to 80 bar. Liquid reaction samples were analyzed offline using gas chromatography coupled with mass spectrometer (Shimadzu QP5050) using HP-5 column. Gas samples were taken out from the autoclave in a $100 \mathrm{ml}$ gas tank and injected with a gas syringe on a gas chromatography (Agilent, 7890A) equipped with a thermal conductivity detector (TCD), split/splitless injection system and Porapak Q column.

\section{Competing interests}

Both authors declare no competing financial interest.

\section{Authors' contributions}

This research conception is carried out in constructive discussions between SPL and AR. SPL who carried out the synthesis, characterization and deoxygenation studies wrote out the content of manuscript based on the analysis and data interpretation. AR was involved in revising this manuscript critically for key intellectual content. Both authors read and approved this final manuscript before submission.

\section{Acknowledgements}

The financial support from Universiti Teknologi PETRONAS under STIRF grant $(82 / 09.10)$ is gratefully acknowledged.

\section{Author details}

${ }^{1}$ Chemical Engineering Department, Universiti Teknologi PETRONAS, Bandar Seri Iskandar, 31750 Tronoh, Perak, Malaysia. ${ }^{2}$ Fundamental and Applied Science Department, Universiti Teknologi PETRONAS, Bandar Seri Iskandar, 31750 Tronoh, Perak, Malaysia.

Received: 22 May 2013 Accepted: 2 September 2013 Published: 5 September 2013

\section{References}

1. Gunter A, Irion WW, Nevwirth OS: Oil refining. In Handbook of fuels. Edited by Elvers B. Germany: WILEY-VCH Verlag GmbH \& Co. KGaA Weinhem; 2008:17-95.

2. Secretariat for the United Nations Framework Convention on Climate Change: Kyoto protocol to the United Nation Framework Convention on Climate Change. UN Doc FCCC/CP/1997/7/Add.1, Dec. 10, 1997; 37 ILM 22 1998. Available from: http://unfccc.int/essential_background/kyoto_ protocol/background/items/1351.php. 
3. Jos GJ O, Greet J-M, Jeroen AHW P, Julian W: Long-term trend in global $\mathrm{CO}_{2}$ emissions 2011 report background studies. Hague: PBL Netherlands Environmental Assessment Agency; 2011:1-42. 500253004.

4. Chen S, Yokoi T, Tamg C, Jang L, Tatsumi T, Chan JCC, Cheng S: Sulfonic acid-functionalized platelet SBA-15 materials as efficient catalysts for biodiesel synthesis. Green Chem 2011, 13:2920-2930.

5. Vasudevan PT, Briggs M: Biodiesel production - current state of the art and challenges. J Ind Microbiol Biotechnol 2008, 35:421-430.

6. Bezergianni S, Kalogianni A: Hydrocracking of used cooking oil for biofuels production. Bioresour Technol 2009, 100:3927-3932.

7. Bezergianni S, Voutetakis S, Kalogianni A: Catalytic hydrocracking of fresh and used cooking oil. Ind \& Eng Chem Res 2009, 48:8402-8406.

8. Boda L, Onyestyak G, Solt H, Lonyi F, Valyon J, Thernesz A: Catalytic hydroconversion of tricaprylin and caprylic acid as model reaction for biofuel production from triglycerides. App/ Catal A 2010, 374:158-169.

9. Choudhary TV, Philips CB: Renewable fuels via catalytic hydrodeoxygenation. App/ Catal A 2011, 397:1-12

10. Donnis B, Egeberg RG, Blom P, Knudsen KG: Hydroprocessing of bio-oils and oxygenates to hydrocarbons understanding the reaction. Top Catal 2009, 52:229-240.

11. Lestari S, Maki-Arvela P, Bernas H, Simakova O, Sjoholm R, Beltramini J, Lu GQM, Mylloyoja J, Simakova I, Murzin DY: Catalytic deoxygenation stearic acid in continuous reactor over a mesoporous carbon-supported Pd catalyst. Energy Fuel 2009, 23:3842-3845.

12. Knothe G: Biodiesel and renewable diesel: a comparison. Progress in Energy and Comb Sci 2010, 36:364-373.

13. Kubicka D, Bejblova M, VIk J: Covnversion of vegetable oils into hydrocarbons over CoMo/MCM-41 Catalysts. Top Catal 2010, 53:168-179.

14. Kwon KC, Mayfield H, Marolla T, Nichols B, Mashburn M: Catalytic deoxygenation of liquid biomass for hydrocarbon fuels. Renew Energy 2011, 36:907-915.

15. Senol Ol, Viljaya T-R, Krause AOl: Hydrodeoxygenation of methyl esters on sulphided $\mathrm{NiMo} / \mathrm{Y}-\mathrm{Al}_{2} \mathrm{O}_{3}$ and $\mathrm{CoMo} / \mathrm{Y}-\mathrm{Al}_{2} \mathrm{O}_{3}$. Catal Today 2005, 100:331-335.

16. Yang Y, Ochoa-Hernandez C, O'Shea V, de la Pena A, Coronado JM, Serrano DP: $\mathrm{Ni}_{2} \mathrm{P} / \mathrm{SBA}-15$ as a hydrodeoxygenation catalyst with enhanced selectivity for the conversion of methyl oleate into n-octadecane. ACS Catal 2012, 2:592-598.

17. Huber GW, Iborra S, Corma A: Synthesis of transportation fuels from biomass: chemistry, catalysts, and engineering. Chem Rev 2006, 2:40044-4098

18. Kubickova I, Kubicka D: Utilization of triglycerides and related feedstocks for production of clean hydrocarbon fuels and petrochemicals. Waste and Biomass Volarization 2010, 1:293-308.

19. Snare M, Kubickova I, Maki-Arvela P, Eranen K, Murzin DY: Heterogeneous catalytic deoxygenation of stearic acid for production of biodiesel. Ind \& Eng Chem Res 2006, 45:5708-5715.

20. Simakova I, Simakova O, Maki-Arvela P, Simakova A, Estrada M, Murzin DY: Deoxygenation of palmitic and stearic acid over supported Pd catalysts: effect of metal dispersion. App/ Catal A 2009, 355:100-108.

21. Snare M, Kubickova I, Maki-Arvela P, Chichova D, Eranen K, Murzin DY: Catalytic deoxygenation of unsaturated renewable feedstocks for production of diesel fuel hydrocarbons. Fuel 2008, 87:933-945.

22. Lestari S, Maki-Arvela P, Simakova I, Beltramini J, Lu GQM, Murzin DY: Catalytic deoxygenation of stearic acid and palmitic acid. Catal Lett 2009, 130:48-51.

23. Kubickova I, Snare M, Eranen K, Maki-Arvela P, Murzin DY: Hydrocarbons for diesel fuel via decarboxylation of vegetable oil. Catal Today 2005, 106:197-200.

24. Simakova I, Simakova O, Maki-Arvela P, Murzin DY: Decarboxylation of fatty acids over Pd supported on mesoporous carbon. Catal Today 2010, 150:28-31.

25. Madsen AT, Ahmed EH, Christensen CH, Fehrmann R, Riisager A: Hydrodeoxygenation of waste fat for diesel production: study on model feed with Pt/alumina catalyst. Fuel 2011, 90:3433-3438.

26. Immer JG, Lamb HH: Fed-batch catalytic deoxygenation of free fatty acids. Energy Fuel 2010, 24:5291-5299.

27. Ping EW, Wallace R, Pierson J, Fuller TF, Jones CW: Highly dispersed palladium nanoparticles on ultra-porous silica mesocellular foam for the catalytic decarboxylation of stearic acid. Microporous Mesoporous Mater 2010, 132:174-180.
28. Zhao D, Feng J, Huo Q, Melosh N, Fredrickson G, Chmelka B, Stucky G: Triblock copolymer syntheses of mesoporous silica with periodic 50 to 300 angstrom pores. Sci 1998, 279:548-552.

29. Yuranov I, Moeckli P, Suvorova E, Buffat P, Kiwi-Minsker L, Renken A: Pd/SiO catalysts: synthesis of $\mathrm{Pd}$ nanoparticles with the controlled size in mesoporous silicas. J of Mol Cat A 2003, 192:239-251.

30. Chen L-F, Guo P-J, Zhu L-J, Qiao M-H, Shen W, Xu H-L: Preparation of $\mathrm{Cu} / \mathrm{SBA}-15$ catalysts by different methods for the hydrogenolysis of dimethyl maleate to 1,4-butanediol. Appl Catal A 2009, 356:129-136.

31. He C, Zhang F, Yue L, Shang X, Chen J, Hao Z: Nanometric palladium confined in mesoporous silica as efficient catalyst for toluene oxidation at low temperature. App/ Catal B 2011, 111(112):46-57.

32. Kosuge K, Sato T, Kikukawa N, Takemori M: Morphological control of rodand fiberlike SBA-15 type mesoporous silica using water-soluble sodium silicate. Chem Of Mater 2004, 16:899-905.

33. Han P, Wang X, Qiu X, Ji X, Gao L: One step synthesis of palladium/SBA-15 nanocomposites and its catalytic application. J of Mol Catal A 2007, 272:136-141.

34. Naskar MK, Eswaramoorthy M: Significant improvement in the pore properties of SBA-15 brought about by carboxylic acids and hydrothermal treatment. J Chem Sci 2008, 120:181-186.

35. Galarneau A, Cambon H, Renzo FD, Ryoo R, Choi M, Fajula F: Microporosity and connections between pores in SBA-15 mesostructured silicas as a function of the temperature of synthesis. New J Chem 2003, 27:73-79.

36. Naik B, Ghosh NN: A review on chemical methodologies for preparation of mesoporous silica and alumina based materials. Recent Pat Nanotechnol 2009, 3:213-224.

37. Galarneau A, Cambon H, Renzo FD, Fajula F: True microporosity and surface area of mesoporous SBA-15 silicas as a function of synthesis temperature. Langmuir 2001, 17:8328-8335.

38. Guo W, Park J, Oh M, Jeong H, Cho W, Kim I: Triblock copolymer synthesis of highly ordered large-pore periodic mesoporous organosilicas with the aid of inorganic salts much progress has been made recently in the prepa- ration of a new class of organic-inorganic hybrid materials called periodic meso. Chem Mater 2003, 15:2295-2298.

39. Chao M-C, Chang C-H, Lin H-P, Tang C-Y, Lin C-Y: Morphological control on SBA-15 mesoporous silica via a slow self-assembling rate. J Mater SCi 2009, 44:6453-6462.

40. Kosuge K, Kubo S, Kikukawa N, Takemori M: Effect of pore structure in mesoporous silicas on VOC dynamic adsorption/desorption performance. Langmuir 2007, 23:3095-3102.

41. Wang P, Wang Z, Li J, Bai Y: Preparation, characterizations, and catalytic characteristics of Pd nanoparticles encapsulated in mesoporous silica. Microporous Mesporous Mater 2008, 116:400-405.

42. Lestari S, Maki-Arvela P, Eranen K, Beltramini J, Max Lu GQ, Murzin DY: Diesel-like hydrocarbons from catalytic deoxygenation of stearic acid over supported Pd nanoparticles on SBA-15 catalysts. Catal Lett 2009, 134:250-257.

43. Anita R, Lee S-P: Catalytic deoxygneation of methyl oleate with supported Pd on SBA-15. Short term internal research report. Malaysia: Universiti Teknologi PETRONAS; 2012.

44. Yueping $K$, Nongyue $H$, Jian $W$, Pengfeng $X$, Chuwei $Y$, Zuhong $L$ : Investigating the state of Fe and La in MCM-41 mesoporous molecular sieve materials. Colloids Surf A 2001, 179:177-184.

45. Bendahou K, Cherif L, Siffert S, Tidahy HL, Benaissa H, Aboukais A: The effect of the use of lanthanum-doped mesoporous SBA-15 on the performance of $\mathrm{Pt} / \mathrm{SBA}-15$ and $\mathrm{Pd} / \mathrm{SBA}-15$ catalysts for total oxidation of toluene. Appl Catal A 2008, 351:82-87.

46. Ghasem RB, Reihaneh M, Fereshteh J, Zeinab P, Hassan A: Covalent anchoring of copper-Schiff complex into SBA-15 as a heterogeneous catalyst for the synthesis of pyridopyrazine and quinoxaline derivatives. Catal Commun 2012, 27:49-53.

47. Simacek P, Kubicka D, Sebor G, Pospisil M: Hydroprocessed rapeseed oil as a source of hydrocarbon-based biodiesel. Fuel 2009, 88:456-460.

doi:10.1186/1752-153X-7-149

Cite this article as: Lee and Ramli: Methyl oleate deoxygenation for production of diesel fuel aliphatic hydrocarbons over Pd/SBA-15 catalysts. Chemistry Central Journal 2013 7:149. 